\title{
Identidad marginal entre personas sin hogar de la ciudad de Temuco, Chile
}

\author{
Marcelo Berho C. ${ }^{1}$
}

\section{RESUMEN}

El presente trabajo constituye una breve síntesis antropológica teórica y sustantiva en que se establecen algunos aspectos del proceso de configuración de una identidad socialmente desacreditada. A partir de una base de datos cuanti-cualitativos derivados de una serie de acercamientos etnográficos -realizados entre 1998 y 2005-, centrados en los mundos de la vida de unas sesenta personas sin hogar de una ciudad de Chile ${ }^{2}$, se proporciona una visión condensada del proceso de configuración de su identidad, advirtiendo sus principales fases y las características psico-socio-culturales de los perfiles asociados a dicho proceso.

Palabras clave: procesos, configuración, identidad marginal, personas sin hogar.

\begin{abstract}
The author presents a theoretical and substantive anthropological synthesis of the identity configuration process among homeless people in a city of southern Chile. From an ethnographic perspective of about sixty homeless' worlds of life, the author establishes the main phases and the psycho-socio-cultural traits of the profiles in relationship with the configuration of marginal identity process.
\end{abstract}

Key words: processes, configuration, marginal identity, homeless people.

${ }^{1}$ Antropólogo, Universidad Católica de Temuco, Chile. mberho@uctemuco.cl

${ }^{2}$ Para la realización de estos acercamientos conté con el irrestricto apoyo intelectual del Centro de Estudios Socioculturales (CES) de la Universidad Católica de Temuco. 
Revista CUHSO volumen $11 \mathrm{n} \div 1$

\section{INTRODUCCIÓN}

El enfoque de trabajo adoptado en el presente texto asume que el análisis de las diferentes experiencias de vida de las personas sin hogar permite la reconstrucción teórica del proceso de configuración de la identidad marginal. Desde el punto de vista metodológico, para esta reconstrucción se han considerado los siguientes aspectos: 1) los relativos a la dimensión estructural o anatómica de la categoría social; 2) los relativos a las prácticas sociales e individuales desplegadas por las personas en el mundo cotidiano; y en menor medida 3) los constitutivos de las interpretaciones o visión del mundo de las personas. Así, este enfoque considera un acceso a y un análisis de datos de diferente naturaleza, tanto cualitativos como cuantitativos. Además, cada uno de estos niveles de realidad han sido analizados respecto de tres ej es fundamentales de estructuración del proceso identitario, a saber, la relación de la persona con el mundo, con los otros y con sí misma, de tal manera de ofrecer una mirada de la configuración de la identidad de las personas sin hogar como un proceso relacional complejo en el que lo individual se fragua y halla incrustado en 10 social - cultural global.

Asimismo, siguiendo algunos principios metodológicos clásicos de la etnografía, se ofrece una lectura en que los procesos de configuración identitaria son observados tanto desde el punto de vista de los actores como del etnógrafo. En el primer caso, se busca captar los puntos de vista nativos, ya sea mediante la ilustración de las propias simbolizaciones de las personas -en cursivas y que por espacio, han sido más o menos suprimidos so pena de perder la frescura y fuerza de la expresión lingüística de actores vivos-, o bien encaminando descripciones comprensivas de sus experiencias, situaciones, relaciones y procesos constitutivos de sus modos de ser y vivir. En el segundo caso, en tanto, se han establecido relaciones y diferencias, se han levantado categorías tipológicas y se han establecido inferencias conceptuales a partir de lo observado, lo oído y lo comprendido. Por último, en la medida de lo posible estas construcciones se han contextualizado en el marco de la sociedad de la que tanto las personas sin hogar como el antropólogo son parte.

Se espera que el presente material sirva tanto a los estudiantes de los procesos identitarios entre grupos marginales como a las instituciones que buscan "ayudarlos". Tanto las descripcionescomolasinterpretacionesvertidas en el texto buscan contribuir al entendimiento general de una realidad social dramática que requiere ser conocida en profundidad y en la cual todos estamos involucrados. El estudio antropológico de la identidad marginal sugiere que ésta se configura de cara al mundo social y sus determinaciones materiales y simbólicas. Aun cuando nos enfoquemos en las personas no podemos dejar de llamar la atención sobre las estructuras que condicionan sus circunstancias de vida. La tarea del antropólogo es gratificada si a través de su conocimiento logra provocar algún tipo de movimiento en sus lectores. Nos sentiríamos satisfechos si este movimiento ha resultado ser interpelador y si simultáneamente ha operado en el otro en términos polisémicos articulando lo intelectual con lo político y lo ético.

\section{CONTEXTO SOCIAL}

Temuco es la ciudad capital de la región de La Araucanía, en el centro - sur de Chile. Antiguamente conocida como la capital de La Frontera ${ }^{3}$, en Temuco habitan actualmente un poco más de 250 mil personas (de las 900 mil de la región), mayoritariamente de origen mestizo -indígena y español- y criollo -descendientes de españoles- $y$, en menor medida, indígenas mapuche y descendientes de colonos europeos -alemanes, suizos, italianos, franceses y vascos-.

Actualmente, Temuco se caracteriza por ser una ciudad comercial y de servicios

\footnotetext{
3 La que gozó de autonomía territorial, política, económica y cultural durante todo el período colonial hasta 1881, momento en que, tras la derrota militar del pueblo mapuche por parte del ejército republicano, es anexada al territorio nacional.
} 
que ha vivido un acelerado proceso de crecimiento durante los últimos veinte años. Frente al despegue de la economía terciaria y la mantención de la producción agropecuaria más o menos tradicional, la región -y la capital- se caracteriza por estar atravesada por sendos problemas sociales, destacando por su dramatismo y persistencia la extrema pobreza y la marginalidad social de algunos segmentos de su población, ligados fuertemente a la ruralidad y la presencia de poblacion indígena (aprox. 65\% y 10\%, respectivamente).

La región de La Araucanía lidera Ios índices de pobreza a nivel nacional con cerca de un tercio de su población en situación de pobreza, distribuida en un $20,1 \%$ de pobres y un $8,9 \%$ de indigentes ${ }^{4}$.

En términos relativos, la región detenta un $9 \%$ del total de la población nacional que vive en situación de pobreza, siendo la Región Metropolitana la que mayor cantidad de pobres concentra a escala nacional: un $31,5 \%$ (MIDEPLAN, 2000: 9).

Desde el punto de vista de las políticas sociales implementadas en los últimos años, contamos con antecedentes del período de 1998 - 2000, período en que, a pesar de la crisis económica global, conocida como crisis asiatica, "el país fue capaz de mantener y fortalecer un amplio conjunto de programas sociales orientados a mejorar la calidad de vida de los hogares en situación de pobreza". Durante estos años, en efecto, el gasto fiscal en materia social alcanzó un 18,6\% y en el año 2000 representó un 34,6\%y un 59,1\%“del mismo excluyendo el gasto en previsión (descontando pensión asistencial)" (Ibíd.: 15)5.
No obstante este esfuerzo -y a diferencia de los países desarrollados-, en Chile no se cuenta con políticas o programas que aborden y cubran el fenómeno en toda su complejidad ${ }^{6}$. En efecto, el gasto social del gobierno no llega aún a esta porción de la población que, de acuerdo a la información oficial, sobrepasa las siete mil personas? ${ }^{7}$. En el caso de la región, se registra un déficit de pensiones de invalidez y vejez que llega a las 1.300 personas, al tiempo que, como han indicado algunos parlamentarios, estos casos Ilevan esperando ser atendidos hasta por tres años. Asimismo, lasformas de asi stencia privadas -formales o informales, profesionalizadas o no, publicitadas o anónimas- tampoco han tenido la capacidad suficiente para ofrecer oportunidades a las cientos y miles de personas que cada año reciben su apoyo.

Desde el punto de vista del Estado, sólo son considerados objetos de políticas de atención especial aquellaspoblacionesincluidas en alguna de las siguientes categorías: infancia, juventud, adulto mayor, mujer, personas con discapacidad, familias en extrema pobreza e indígenas. Estas categorías de persona han pasado a ser consideradas como "grupos prioritarios" tras habérseles identificado como "grupos vulnerables". Sin embargo, desde el punto de vista social se advierte una disposición favorable a asistir a la población que vive en situación de marginalidad extrema, la cual, como lo han venido señalando desde hace un tiempo diversos agentes sociales a nivel nacional, no sólo debe ser objeto de la caridad y la mera asistencia sino, fundamentalmente, de justicia.

\footnotetext{
${ }^{4}$ Seguida por la región del Bío - Bío, con un 27,9\% la III, VII, IV, X y V regiones, entre un 24,3\% y un 19,3\%

${ }^{5}$ En términos específicos, el gasto social fiscal durante el 2000 fue destinado a los siguientes ámbitos: 1) subsidios monetarios (asignación familiar, pensiones asistenciales (PASIS), subsidio único familiar, subsidio al consumo de agua potable y subsidio de cesantía; 2) subsidio en salud (atenciones y Programa Nacional de Alimentación Complementaria); y 3) subsidio en educación (subvenciones escolares, programas de textos, útiles, salud escolar, salud oral y Programa de Alimentación Escolar). De acuerdo a MIDEPLAN, a fines del año 2000, fueron 78.519 hogares los que recibieron algún tipo de subsidios sociales del Estado chileno. Los beneficios entregados a través de los programas de subsidio social representaron "el equivalente a un incremento del ingreso autónomo promedio de 193,9\%para los hogares indigentes, de 63,9\% para los hogares pobres no indigentes y de 79, \%para los hogares pobres en conjunto" (Ibíd.: 13). La mayor parte de estos subsidios se destinaron al ámbito educacional, con un total de 44.819 subsidios, distribuidos fundamentalmente entre la enseñanza básica (con 30.279 subsidios), seguidos por los otorgados para la enseñanza media y la pre-escolar (con 8.707 y 5.363 subsidios respectivamente). En importancia le sigue el ámbito de la salud, con un total de 23.980 subsidios.

${ }^{6}$ En julio de 2005 se llevaría a cabo el primer Catastro Nacional de "Personas en Situación de Calle", el que ha sido concebido como un instrumento clave para dimensionar el problema a escala nacional y regional, así como para diseñar políticas encaminadas a otorgar beneficios a la población

${ }^{7}$ En el caso de Temuco, el Catastro registraría un número superior a las 150 personas.
} 
Una de las características que quizá por ser la más evidente y, por lo mismo, la que menos atención ha recibido de parte de los diferentes sectores o componentes sociales que, tanto en Chile como en América Latina, se han preocupado del problema de la marginalidad de las personas sin hogar, es la ausencia de vivienda, así como de programas especiales para tener acceso a ella.

Sólo para el caso de la región de La Araucanía, y de acuerdo a los datos de la Encuesta Casen 2000, en La Araucanía se requeriría reponer cerca de 30.000 viviendas. Esto significa que existe un déficit habitacional de un $12 \%$ en la región. No obstante, de acuerdo a los registros de inscritos en los programas habitacionales del gobierno, la cifra se eleva a un total de 42.314 familias que demandan vivienda. Si bien no existen cifras respecto de la proporción de gente que no cuenta con una vivienda donde habitar, las cifras antes señaladas pueden considerarse un factor desencadenante de sin hogarismo, así como una suerte de indicador empírico ligado a la pobreza y la marginalidad regional.

En términos relativos, el porcentaje de déficit antesseñalado, varía considerablemente entre las comunas de la región. Así, mientras para la comuna de Los Sauces, el déficit es superior al 30\%, para Temuco es menor a un $10 \%$ más precisamente alcanza a un $6,2 \%$ (de un total de 61.337 familias). No obstante, la mayor demanda habitacional corresponde precisamente a esta última comuna, a pesar de que la mayor inversión se registra para el caso de las otras comunas (Seremi de Vivienda y Urbanismo, 2003). En términos de demanda de vivienda en la comuna, la cifra asciende a un total de 13.924 familias. La misma fuente indica que "un $88,7 \%$ de la demanda registrada en la región la concentran las líneas de atención destinadas a la población de menores recursos". De este porcentaje, "sobre un 30\% de la población regional... está en condición de pobreza" y/o indigencia (Ibíd.: 25).

\section{Personas sin hogar en Temuco}

Partiendo de una base de datos de sesenta personas sin hogar de la ciudad de Temuco ${ }^{8}$, se puede afirmar que las personas que viven en una situación de "sin hogarismo" (del inglés homelessness) en dicha ciudad son, en su mayoría, hombres, solteros y separados, de origen chileno, cuyas edades oscilan entre los 21 y 75 años de edad, con un promedio de 47 años de edad.

Excluyendo a los ancianos mayores de 65 años así como a los discapacitados, la mayoría de estos hombres se encuentra en una edad económicamente activa, lo que resulta interesante desde el punto de vista sociológico. En una sociedad donde la idea de trabajo, productividad y voluntad individual de superación, competitividad y eficiencia forman parte del sistema de valores, todo aquel que se encuentre en condición productiva y no desarrolle actividad alguna orientada por dichos valores, es obj eto de evaluaciones negativas. En nuestro caso, el no incorporarse a actividades productivas formales y no poseer impedimentos para realizarlas, convierte a la persona automaticamente en "ocioso", "mendigo", "vagabundo", "alcohólico", etc., categorias éstas que, de acuerdo a las observaciones, pueden representar potentes, aunque sutiles, criterios de discriminación social.

Cabe advertir que no obstante el juicio social predominante, las personas sin hogar sí desarrollan actividades económicas. De lo contrario, simplemente no podrían sobrevivir. Volveremos sobre este punto más abajo, una vez que entremos plenamente al objeto de nuestro interés.

Otro hecho de interés sociológico emerge cuando comparamos el estado civil de las personas sin hogar con el de la población de la comuna de Temuco. Las diferencias entre los casados en ambas poblaciones resulta ser abismante ${ }^{9}$, mientras que la relación inversa se

\footnotetext{
${ }^{8}$ Equivalente, según las cifras del Primer Catastro Nacional de Personas en Situación de Calle (MIDEPLAN, 2005), a un poco menos de la mitad de la población de la comuna.

${ }^{9}$ Llegando al orden de los 54,1 puntos porcentuales a favor de la población comunal.
} 
da entre los separados, donde la diferencia es a favor de las personas sin hogar ${ }^{10}$. Asimismo, las personas sin hogar se caracterizan por sobrepasar casi cinco veces a la población de viudos de Temuco.

Contrariamente al supuesto social que afirma una correspondencia entre indigencia y analfabetismo y bajo nivel de instrucción, el acercamiento etnográfico a personas sin hogar de Temuco, y más específicamente la documentación estadística desplegada dentro de este mismo, arrojó como resultado la existencia de una mayoría de personas que han cursado prácticamente todo el ciclo primario de educación formal (primero a octavo año básico) ${ }^{11}$. Cabe señalar que esta situación es bastante diferente en comparación con la de muchas provincias y comunas del país ${ }^{12}$. Por último, no se ha registrado ningún caso de analfabetismo y sí personas con estudios secundarios completos y unos pocos con estudios técnico - universitarios.

Considerando estos datos, se pone en entredicho el supuesto de sentido común que señala que las personas sin hogar carecen de educación o son analfabetos, lo que desde ese mismo razonamiento explicaría su "anormalidad". Muy por el contrario, como hemos dicho, las personas sin hogar en Temuco poseen promedios altos respecto de otras poblaciones, lo que representa una singularidad en términos socioculturales.

Por otro lado, las personas sin hogar son y han sido histórica y socialmente categorizadas como "vagabundos" y" deambulantes" (Bauman, 2003), etiquetas que hacen referencia a una constante movilidad. En un sentido analítico, la movilidad geográfica es clave para entender la desvinculación comunitaria y el desarraigo de estas personas; desde el punto de vista etnográfico, en tanto, hay una relación directa entre esta conducta y la carencia de hogar. En nuestro caso se observa que, en su mayoría, las personas son oriundas de la ciudad de Temuco y de la IX región, y prácticamente no habían salido de allí, mientras que menos de un $1 / 5$ provenía de otros lugares. Estas dos últimas categorías representan un poco menos de la mitad de las personas que declararon no ser originarias de Temuco, lo que condice la idea social (y académica) de movilidad geográfica entre las personas sin hogar, aunque ésta no sea de gran alcance y se realice, más bien, dentro de un área limitada -fundamentalmente la region-.

No obstante lo anterior, podemos señalar que si bien las personas sin hogar experimentan cierto grado de movilidad geográfica, es imposible afirmar que se trate de un rasgo identitario. En este sentido, la migración de poblacion mapuche desde la región sobrepasa ampliamente la registrada en cualquier otra población del país. Por último, podemos señalar que la movilidad geográfica poblacional es una característica de nuestros tiempos, asociada a los procesos de globalización y desterritorialización de las comunidades, internacionalización de la economía capitalista y búsqueda de nuevas oportunidades de desarrollo social y personal.

El tiempo sin hogar es una variable determinante para comprender la situación de sin hogarismo como una forma de marginalidad, cada vez que a partir de ella se definan rasgos socioculturales entre las personas. En este sentido, si podemos asumir que las personas que llevan menos tiempo viviendo sin hogar reflejan la edad de inicio como personas sin hogar, podemos afirmar que las personas sin hogar que podemos Ilamar "novatas", siguiendo a Grigsby y cols. (1990), son básicamente personas mayores de 30 años; mientras que quienes, en el otro extremo, llevan más tiempo en esta situación -más de cinco años- son personas mayores de 40 años.

Dada la importancia que tiene el tiempo en todo proceso de configuración (físico-natural, psicológico y socio-cultural), y

\footnotetext{
${ }^{10}$ En que llega a los 29, 9 puntos porcentuales.

${ }^{11}$ Estableciéndose un promedio de 7,8 años de estudio.

12 Sobrepasando el promedio de veintiún comunas de la IX Región.
} 
de acuerdo a los datos disponibles, se pueden distinguir algunos perfiles de personas sin hogar según el tiempo que la persona suma viviendo en dicha situación. Así, las personas que han vivido más de cinco años sin hogar y que, en el caso de Temuco, concentra a la mayoría de la población, han sido categorizados en otros estudios como "permanentes" o "atrincherados" (Ibíd.). Más adelante veremos los rasgos socio-culturales de este perfil, aunque podemos adelantar que se trata de personas que despliegan un estilo de vida caracterizado objetivamente por la ausencia de un "hogar" convencional, la distancia con respecto a los espacios de asistencia y protección social públicos y la apropiación de la calle como territorio existencial.

En el otro polo encontramos a las personas que Ilevan menos de un año viviendo sin hogar. Se trata de los "novatos" y los "recientemente desalojados", "personas que tras haber tenido las condiciones mínimas de habitabilidad digna, inician un proceso de desafiliación relacional, emocional e institucional que se ve agravado por la imposibilidad de conseguir un sitio donde poder vivir y de ver aminorado su acceso a los bienes y servicios de la sociedad" (Berho, 2003: 23). Por último, las personas situadas entre uno y cinco años, se caracterizan por atravesar una situación de vulnerabilidad relativa que abarca diferentes perfiles: desde los "experimentados", y "veteranos", hasta los "permanentes" y "atrincherados".

Para cerrar esta primera parte, diremos que, en el caso de Temuco, se observan personas sin hogar de origen étnico mapuche y no mapuche, predominando las de origen no mapuche (o chileno) ${ }^{13}$. Las personas mapuche, en tanto, se caracterizan por llevar más de tres años viviendo sin hogar, estar desvinculados familiarmente, poseer escaso nivel de instrucción -hasta cuarto básico- y presentar conductas alcohólicas en grado diverso.

Por último, otro rasgo significativo entre las personas sin hogar es la presencia algun tipo de handicap fisico, sensorial y psiquico o "discapacidad". Si bien la mayoría de las personas no presentaba ningún tipo de discapacidad, un sector importante de ellos (1/ 5 aprox.) presenta rasgos considerados culturalmente "psicopatológicos" -desórdenes mentales, alucinaciones visuales y auditivas, dificultades para comunicarse- y en menor medida algún tipo de discapacidad física y sensorial (ceguera y sordomudez).

\section{Procesos de configuración identitaria entre las personas sin hogar}

Desde el punto de vista teórico, asumimos que la identidad de las personas sin hogar es en gran medida el producto de un proceso contextualizado de marginalización, desvinculación y adaptación particular -signada por la vida sin hogar- al entorno psico-socio-cultural de la calle. Dado que las personas experimentan este proceso de un modo particular según las relaciones que despliegan con el mundo, la sociedad y la subjetividad, la identidad adquiere rasgos singulares que cristalizan en perfiles mas 0 menos identificables. Nuestra hipótesis de partida en este sentido es que la experiencia de vivir sin hogar es una experiencia fundante en la generación y conformación de los perfiles. De este modo, la configuración identitaria puede concebirse como una "carrera" 14 en que se adquieren, desarrollan y proyectan diversos perfiles, cada uno de los cuales remite a su vez a un conj unto de propiedades individuales, relacionales, adaptativas y culturales que a continuación pasamos a explicitar.

A continuación se expone la estructura de las "carreras" marginales inferida a partir del análisis de las notas de campo y de los relatos biográficos de las personas sin hogar

\footnotetext{
${ }^{13}$ Siguiendo la conceptualización de Da Matta (2002) acerca de las sociedades tradicionales, quizás esta situación obedezca a la estructura holística de la sociedad mapuche, la que se mantiene vigente aún en nuestros días y en la que, a pesar de las transformaciones estructurales derivadas del proceso de integración forzada a la sociedad nacional, el sistema de parentesco de linajes y la estructura de congregación ritual, siguen teniendo centralidad entre los mapuche rurales e incluso urbanos.

${ }^{14}$ En otra parte he expuesto inicialmente algunas de estas ideas. El término "carrera" lo he tomado de Goffman (1991), quien en su libro Estigma se refiere a las carreras morales que siguen las personas estigmatizadas.
} 
en Temuco con quienes se alcanzo mayores niveles de confianza.

1. Ruptura básica o iniciación desatada generalmente a partir de crisis vitales o hechos biográficos de honda repercusión emocional: muerte de seresqueridos, separación, maltrato, vicio, locura, ruina económica. En conjunto estas experiencias refieren a momentos de liminalidad, sufrimiento e infortunio.

2. Desvinculación socio-afectiva (familia y amistades) y socioeconómica (trabaj o, sistemas sociales de protección y apoyo psicosocial).

3. Vulneración dela integridad, correspondiente al momento de abrazo y adquisición de una identidad estigmatizante, relacionada con el abuso de bebidas alcohólicas y una serie de experiencias vitales que inciden en el deterioro del cuerpo (enfermedades, accidentes, violencia urbana, inseguridad) y el desarrollo de procesos adaptativos al mundo de la calle, dado fundamentalmente a partir del despliegue de diversas estrategias de sobrevivencia.

4. Consolidación de un estilo marginal: resignificación del sí mismo y de la calle y de las experiencias de desvinculación social; reestructuración de las expectativas de vida.

Cada una de las fases de una carrera marginal entre personas sin hogar se va construyendo a través de diferentes materiales vitales y en ellas están implicados actores, contextos y experiencias diversas. Así, la partida compromete aún a actores que conforman el núcleo familiar, incluyendo a parientes consanguíneos y/o afines. Los contextos iniciáticos son contextos de drama social y las experiencias vividas representan el desmembramiento, la descomposición y pérdida progresiva de la unidad y el sostén social y afectivo primarios. La materia prima desde la que se proyecta esta experiencia es el sentido de abandono ("quedarse solo"), la ruptura, la desvinculación ("no tengo a nadie") y la incertidumbre ("no sabía qué sería de mí", "no se si mañana sigo vivo") que todo ello desata a nivel subjetivo.

Los relatos vitales de las personas sin hogar, recogidos una vez que el etnógrafo alcanza la suficiente confianza con éstas, enseñan que las adaptaciones comienzan tras episodios de remoción psicosocial que pueden activar una serie de mecanismos de resiliencia sin los cuales el momento por el que éstas atraviesan podría ser insostenible. En algunos de los casos conocidos, la ingesta de bebidas alcohólicas -y en menor medida de sustancias como solventes- y la emergencia de psicopatologías o su presencia previa al momento de ruptura podían afectar gravemente la identidad y disposición personal y relacional de la persona, acelerando el quiebre con los referentes de proximidad y estabilidad social que hasta ese momento daban garantía de cierta seguridad ontológica.

La razón principal que esgrimen las personas para explicar su situación de vivir o estar en lacalle o sin hogar-independientemente del tiempo que llevan en esta situación- tiene que ver con problemas al interior de la familia. En efecto, la mayoría de las personas de las que tengo registro me contó que llegó a la calle debido a rupturas familiares, ausencia de figuras familiares significativas, separación conyugal y/o violencia al interior del hogar; además de la muerte y/o pérdida de seres queridos (especialmente de alguno de los padres o de ambos, así como de la esposa) $y$, por otra, a decisiones voluntariamente inducidas, como ser el abandono de hogar y la búsqueda de nuevos espacios vitales.

Las razones económicas -ligadas a la precariedad laboral y la pérdida de empleo-, en tanto, se ubican en el tercer lugar de importancia, seguidas de los problemas psicosociales derivados directamente del abuso de bebidas alcohólicas, la emergencia de psicopatologías como esquizofrenia $y$, en menor medida, problemas legales derivados de la comisión de delitos ("como tengo mis papeles manchados, nadie me quiere abrir las puertas", "la gente desconfía de uno").

Cabe señalar que los cambios en la estructura del trabajo en Chile, relativos al aumento de la competencia laboral, la mayor cualificación técnica y experta, o la crisis económica de los '90, han jugado en contra de muchas de las personas sin hogar conocidas. Asimismo, no se puede soslayar el hecho de 
Revista CUHSO volumen $11 \mathrm{n} \div 1$

que muchos de los problemas psicosociales identificados se han visto acentuados por la insuficiencia de recursos y servicios especializados, públicos y privados, que puedan prevenirlos, contenerlos y tratarlos apropiadamente ${ }^{15}$.

La importancia que tienen estos datos es sustancial debido a que nos muestra que la situación de marginalidad de las personas no responde a causas necesariamente individuales como se asume desde diversos sectores de la sociedad, incluyendo a algunos sectores políticos y académicos. Al observar las proporciones vemos, más bien, una situación constitutiva de un problema de naturaleza social y relacional primordial ${ }^{16}$.

La importancia que tienen estos datos es sustancial debido a que nos muestra que la situación de marginalidad de las personas sin hogar no responde necesariamente a causas individuales, como se asume desde diversos sectores de la sociedad nacional, incluyendo a algunos sectores políticos y académicos. Al releer las razones dadas por los propios actores vemos, másbien, la expresión de un problema de naturaleza social y relacional primordial. Estos hallazgos son coherentes con las explicaciones dadas en las ciencias sociales contemporáneas que destacan el papel explicativo de las dimensiones socio-relacionales y socioafectivas en la desvinculación o desafiliación social, remitiéndonos a la estructura social primaria, antes que a las características individuales del actor (Castel, 1999; Castel, 2003; Cabrera, 1998) ${ }^{17}$.

Al observar la situación "civil" de las personas sin hogar, podemos señalar que un poco más de la mitad presenta un estado de 1) no conformación del núcleo familiar, mientras que un tercio de ellos 2) experimenta disgregación o disolución del grupo familiar. Esto quiere decir que en su mayoría las personas sin hogar no llegan a desarrollar vínculos posibles o estables que permitan la constitución de lo que, en nuestro marco cultural, denominamos "familia" u "hogar" y que son percibidos como normas: la familia como la unidad social mínima de reproducción, producción y endoculturación, y el hogar como principal núcleo de estabilidad y privacidad. Este vacío se expresará también, a diferencia de otras categorías marginales ${ }^{18}$, en la escasa presencia de nichos de sociabilidad y conformación de una consciencia grupal, durante todo el proceso configurativo.

Asimismo, la mayor parte de las personas sin hogar que inician y desarrollan carreras marginales, se caracterizan porque, por un lado, poseen itinerarios de desestabilidad relacional asociados a la presencia de familias descompuestas, maltrato o violencia familiar, alcoholismo, situaciones de orfandad, etc., en las que se experimentan, por otro lado -como señaláramos más atrás-, sentimientos de pérdida de las figuras significativas: del padre o la madre, la esposa o los hijos. La sensación de sentirse abandonado, a la deriva, desilusionado y desesperanzado que acompañan a estas experiencias y aquellas donde la persona decide romper con una relación afectiva relevante -a causa del engaño y el infortunio-, parecieran ser correlativas en general con el nivel de estructuración y proyección del perfil marginal entre las personas.

\footnotetext{
${ }^{15}$ Desde la última década, en Chile se percibe todo un movimiento institucional en el ámbito de la salud mental que busca reformar el tratamiento de las enfermedades psíquicas y mentales sobre la base de corrientes pos-estructuralistas que asumen que los problemas psiquiátricos tienen su razón de ser en el entorno en que el enfermo se encuentra. Este enfoque impulsa la desinstitucionalización y rehabilitación del paciente dentro de su comunidad de vida. De acuerdo a nuestras observaciones de campo, pareciera ser que con este tipo de medida no sólo se reduce el gasto público en la materia, sino que se puede ayudar a engrosar las filas de marginales. Esta situación probablemente responda a que la sociedad carece de los soportes, mecanismos y condiciones básicas para disminuir el quiebre que experimentan las personas que han vivido dentro de instituciones totalizantes como son los "psiquiátricos" (Foucault, 1993) y que, de pronto, se ven compelidas a tener que abandonarlos y re-iniciar una vida en circunstancias muchas veces hostiles 0 inundadas de incomprensión e intolerancia social.

${ }^{16}$ Estos hallazgos son coherentes con las explicaciones dadas en las ciencias sociales contemporáneas al destacar el papel explicativo que tendrían las dimensiones socio-relacionales y afectivas en la desvinculación o desafiliación social, remitiéndonos a la estructura social primaria del suj eto, antes que a las características individuales de éste (Cabrera, 1998; Castel, 1999), como se sostiene desde perspectivas de sentido común o políticas liberales. De todos modos, es importante señalar que este tipo de situaciones da pie, ante todo, a una discusión más amplia sobre la forma de concebir y buscarle alguna solución a esta problemática.

${ }^{17}$ Este tipo de situaciones debería dar pie a una discusión más amplia sobre la forma de concebir y tratar la problemática.

18 Principalmente grupos étnicos en la ciudad, así como homosexuales, autodenominados "gay".
} 
En este contexto es común oír declaraciones de las personas que señalan no contar con nadie que los pueda ayudar, que es "mejor ni saber de la familia", "ya ni me acuerdo de la familia", "hago como que no tengo ni señora ni hijos", "solito estoy mas tranquilo, no tengo preocupaciones de nada ni de nadie", "cada uno con sus piojos", etc.

Por otro lado, la frustración que experimentan las personas que pierden su trabajo o no logran insertarse laboralmente, a pesar de sus esfuerzos por hacerlo, puede constituir terreno fértil para la emergencia de sentimientos de infortunio y disponer a la persona a proyectar actitudes de autoabandono y auto-aniquilación. En el mejor de los casos, unos pocos abrigan expectativas de cambio que, al no cumplirse, poco a poco van cediendo lugar a la resignación y la desesperanza. Estas últimas situaciones se dan sobre todo entre personas relativamente jóvenes que han llegado a la ciudad en busca de oportunidades para mej orar su nivel de vida, así como también entre personas que, tras la pérdida de familiares o sus parejas, pierden consistencia vital, volviéndose pusilánimes y despojando a la existencia de su sentido anterior.

En general, las personas que más claramente vivencian esta fase del proceso y que desplegarían un perfil "novato" o de "iniciados", personas situadas entre los 21 a 45 años de edad que llevan viviendo sin hogar menos de un año que, a pesar de lo indicado anteriormente, cuentan con redes sociales primarias o de proximidad (familiares y amigos), usan el sistema de asistencia privada, presentan enfermedades psíquicas (45,5\% se sitúa entre los 21 y 36 años) y pueden desarrollar una forma de alcoholismo tendiente a configurar perfiles endo-culturales conocidos como torrantes (ver más adelante). En general, son personas que viven en un estado "fronterizo", puesto que todavía conservan atributos sociales para continuar dentro de la corriente normal de la vida social, aunque desde el punto de vista subjetivo no se sienten lo suficientemente fuertes como para sobreponerse por completo.

El proceso de desvinculación que se pone en marcha tras la ruptura inicial presenta una primera acomodación psicosocial por parte de la persona en la que ésta desarrolla una separación no sólo emocional sino también física de la red de contactos sociales primarios, tras la aceptación a regañadientes que hace de su nuevo estado. No obstante, este proceso puede tomar tiempo. En efecto, hemos conocido personas que no Iogran superar la desgracia de perder un ser querido durante mucho tiempo, circunstancia que se va agravando cada vez más al desvalorizarse a sí mismas y perder la esperanza de efectuar cambios en sus vidas.

Durante esta fase, la persona comienza a desagregarse de los soportes de socialización, los que ve incapaces de responder a sus exigencias: vacíos existenciales que ni la familia, el trabajo o la asistencia pueden Ilenar. En estos contextos, quien Ilega a la calle se ve enfrentado a una situación de progresiva desvinculación, a la vez que de adaptación y transformación de su estilo de vida e identidad, pudiendo ésta llegar a estar a tono o no con las categorías sociales usadas para simbolizar a y relacionarse con quien vive de esa forma. En efecto, las personas sin hogar pueden o no usar, apropiar, invocar, evocar y re-significar algunos objetos, espacios, referentes, símbolos y contenidos de la identidad pública y del entorno sociocultural en el cual se desenvuelven, posicionándose de manera variable en ellos y construyendo su identidad en la tensión estar dentro / estar fuera, Ser Uno / Ser Otro.

Gran parte de la adaptación que requiere operar la persona concierne al como resolver las necesidades básicas. Una vez sin hogar, la persona debe enfrentar cada día la cuestión de la alimentación y la bebida, la protección, el abrigo, el descanso y la seguridad. Es más, debe decidir qué hará si no quiere morir. La persona descubre lo imperioso que es que la necesidad sea cubierta. Descubre 
también que para que así sea debe modular su conducta al entorno de la "calle" (ver más adelante). Esta comienza poco a poco a convertirse en un territorio para vivir, donde es posible extraer lo necesario para sobrevivir (ver más adelante). Algunas personas experimentan sendas crisis emocionales que sólo alivian momentáneamente embriagándose - fantaseando. Otros sienten deseos de morir o de acabar con la vida que Ilevan. Pueden ser muy críticos hacia la sociedad o ni siquiera esbozar que sus existencias se hallan entrelazadas. Durante esta fase las personas tienen experiencias y sentimientos de discriminación social ligadas al cambio de su apariencia. Es obvio que todas estas experiencias surten profundos efectos sobre la configuración identidad social y subjetiva de la persona. Sin poder determinar aún claramente como todo esto ocurre, podemos afirmar que lo que esta en juego es la consistencia relacional y el sentido de la vida.

En este contexto, juegan un rol importante las redes de apoyo que existen en el marco de la asistencia social de la ciudad -conformada por un conjunto de instituciones públicas y privadas- ${ }^{19}$, las cuales brindan servicios básicos -alojamiento, alimentación, vestuario, atención en salud, orientación previsional, etc.- que los soportes sociales de integración no logran cubrir.

La estrategia de acceder tanto a redes públicas como privadas es la mayormente desplegada por las personas en esta fase del proceso, seguida por quienes utilizan todas las formas posibles de ayuda o apoyo, vale decir, del sistema público y privado, incluyendo a familiares, amigos o conocidos con quienes existe confianza. Dada la invisibilidad del fenómeno a nivel público, no debe llamar la atención el bajo porcentaje de personas que utilizan solamente el sistema de asistencia o red pública de apoyo.
La red más utilizada por las personas varía en función de sus edades. Así tenemos que quienes usan todos los tipos posibles o disponiblesson laspersonas menores de 45 años, es decir, que la conducta sociocultural de las personassin hogarmásj óvenes, tendería haciala maximización de las escasas oportunidades que el medio provee. Al contrario, las personas que recurren principalmente a las redes públicas y privadas, estableciendo así una estrategia más convencional, son las personas de mayor edad, donde el elemento discriminante corresponde al vínculo con familiares y amigos. De acuerdo a los datos disponibles, sostenemos que la edad estaría asociada al tamaño de la red total de las personas, donde la hipótesis a contrastar afirmaría que, a mayor edad, menor tamaño de la red, y, a la inversa, a menor edad, mayor será el tamaño de la red de las personas sin hogar.

Durante esta fase parecieran establecerse con propiedad las actividades económicas que cada una de las personas realizará mientras siga en situación de sin hogarismo. Si durante la primera fase, las personas sin hogar desarrollaban actividades económicas "informales", en la fase de desvinculación emergen y se desarrollan otras formas: mendicidad y recolección. Las actividades informales abarcan actividades como la "venta ambulante" de objetos de uso cotidiano (aguj as de coser, parchespara heridas, pinches para el pelo, manteles de cocina) $u$ otras actividades situacionales conocidas como "pololos" o "changuitos" 20 (cuidado de vehículos, carga y descarga de camiones, "carretoneo", traslado de bultos, entre otras). Estas actividades son ej ercidas principalmente por personas que responden al perfil de los "experimentados" correspondiente, desde el punto de vista de los actores, al perfil de los torrantes, quienes se desenvuelven mas 0 menos espontáneamente en lugares populares

\footnotetext{
${ }^{19}$ En Temuco, hasta el 2005, han existido unas diez de estas instituciones, generalmente de derecho privado. La característica común de estas instituciones es su orientación asistencial caritativa más o menos profesionalizada.

${ }^{20}$ Trabajos de poca monta, aunque puedan requerir el uso de la fuerza.

${ }^{21}$ En el caso de Temuco, este espacio es fundamentalmente el que se conoce como Feria Pinto y, en general, el sector Estación de Temuco. Este es un espacio tradicional de comercio de productos agropecuarios al que confluyen diferentes actores sociales, mapuche y no mapuche, provenientes de sectores rurales aledaños y de la propia ciudad. Además hay en él un terminal de buses rurales, la estación de ferrocarriles, supermercados, tiendas comerciales, mayoristas y minoristas, ferreterías, tiendas de ropa usada, bazar -conocido como "feria de las pulgas" - y una amplia gama de cantinas y restaurantes.
} 
UNIVERSIDAD CATÓLICA DE TEMUCO

y bulliciosos de la ciudad ${ }^{21}$.

La mendicidad es una actividad económica en que la persona pide dinero o comida directamente a un transeúnte 0 a veces a los moradores de un hogar. En ambos casos, estas actividades son desarrolladas mayormente por personas ancianas, personas con alguna discapacidad física o jóvenes en un visible estado de deterioro físico, producto del exceso de alcohol y/o la acumulación de enfermedades sin tratar. Generalmente las podemos encontrar en las afueras de iglesias, centros comerciales, paseos peatonales, etc. Se ha constatado que algunos de estos sitios son prácticamente concebidos como lugares de trabaj o por quienes ej ercen la mendicidad. Esta actividad puede llegar a ser muy bien evaluada por quienes requieren dinero para pagar sus gustos y urgencias: alcohólicos inveterados, personas que necesitan mayor protección (y prefieren dormir en hospederías) y quienes, por último, mantienen hábitos alimenticios e higiénicos más o menos corrientes (y que pagan para comer y asearse).

Quienes desarrollan actividades de recolección de desechos son la minoría. Dentro de esta actividad se puede distinguir la recolección comercial y la orientada a la subsistencia. Mientras el primer tipo de recolección es realizado esencialmente por personas mayores de 45 años -que se autodefinen 0 no como torrantes-, el segundo concierne a una práctica propia de marginales sin hogar que en otra parte denominamos como "alucinatorios" y "profesionales", aunque con frecuencia se puede observar también entre personas que tienen una trayectoria de pobreza previa y que, por diversos motivos, terminan viviendo en la calle. En el primer caso, las personas buscan latas de bebida o cerveza, botellas de vidrio o plástico, cartón y metales. En el segundo, las personas auscultan en busca de comida, ropa, calzado, botellas, tiestos o cualquier utensilio que puedan reciclar para uso personal ${ }^{22}$. En cualquiera de los casos señalados, las personas tienen una ruta que recorren habitualmente en función de obtener lo que buscan.

Todas estas prácticas muestran una relación adaptativa diferente a la que habitualmente se establece con "la calle". $\mathrm{Si}$ bien todos los miembros de una sociedad urbana "salen" de sus casas a "la calle", en el caso de las personas sin hogar, no se sale sino que se está ya en ella. Así, mientras los ciudadanos salen corrientemente de sus hogares a sus trabajos, la calle no es en ellos, como sí lo es entre las personas sin hogar, en propiedad su espacio laboral. Y esto es así aun cuando la oficina, la tienda, el mesón, etc. no sean ni la casa ni la calle.

Por otro lado, de acuerdo al registro documental, un décimo de las personas se mantienen, aún dentro de esta fase, con los ingresos reportados a partir del cobro de pensiones, lo que nos muestra un hecho significativo: que existe una cobertura mínima de acceso a los beneficios asistenciales del Estado, es decir, que éste no constituye un soporte de socialización entre las personas sin hogar. En este caso, generalmente se trata de ancianos, jubilados y personas con discapacidad que han recibido atención previsional una vez en la calle. En el caso de ancianos y personas sin hogar discapacitadas -especialmente con discapacidad psíquicalos beneficios que obtienen generalmente a acciones emprendidas para dichos efectos por agentes institucionales sensibles al problema social en encarnado por las personas.

Otra experiencia constitutiva en el proceso identitario entre los marginales es la de pernoctar. De acuerdo a las conversaciones con ellos y a las propias observaciones de campo, se ha determinado que, al igual que en el caso de las prácticas económicas, existe un abanico de posibilidades relativas a los sitios donde pernoctar. Así, las personas pueden dormir en espacios prestados -como "allegados"-, hospederías u otros servicios sociales y en la calle. En el caso de Temuco, más de la mitad de las personas ya "experimentadas" duerme en hospederías y en la calle, mientras que menos

\footnotetext{
${ }^{22}$ En mi experiencia de campo conocí una persona que obtenía todo lo que necesitaba para vivir de la basura. Se consideraba a sí mismo, entre otras definiciones, un "Iimpiador" y, a nuestro juicio, podríamos caracterizarlo también como un "acumulador". Cabe resaltar que esta persona no usaba dinero. En base a este caso y a otro par de personas es que levantamos la categoría de personas sin hogar "profesionales".
} 
de un décimo, generalmente los "novatos", Io hace en un espacio facilitado por algún familiar, amigo o conocido. Asimismo, algunos ancianos, enfermos, alcohólicos o pacientes psiquiátricos pueden acceder, cuando aceptan hacerlo, a hogares de ancianos, hospitales o centros de rehabilitación, sin que existan establecimientos exclusivos para los de su tipo ${ }^{23}$.

En el punto de mayor territorialización de "la calle" algunas personas prefieren dormir en ésta, lo que da cuenta de una inversión del "hogar", "la casa" como el espacio donde se debe dormir y despertar cada mañana. Asimismo, es otra muestra de la ausencia de relaciones con la familia, amigos o cercanos en los cuales poder confiar, así como de desvinculación institucional -básicamente con las hospederías u otro tipo de centros de asistencia social. Cabe señalar que dentro de la "calle" las personas distinguen lugares más o menos cómodos: bancos de plaza, portales de viviendas o edificios públicos y privados, centros comerciales, faldas del cerro, puentes, sitios eriazos, se consideran "malos" sitios para pasar la noche; mientras que los vehículos o casas abandonadas, los hospitales, centros de urgencia y portales cubiertos o protegidos son mejor evaluados. La elección de esos lugares no es azarística: responde a las circunstancias climáticas, las preferencias piscosociales, el nivel de familiaridad o adaptación a las condiciones de la calle y el grado de intemperie alcohólica, entre otros aspectos.

En el otro extremo se encuentran las hospederías y otros establecimientos privados, que ofrecen mejores condiciones y comodidades que la calle, pero cuyo acceso está mediado por el pago de un monto de dinero -lo que exige el desarrollo de estrategias para su obtención-, y que imponen al sujeto la necesidad de tener que desenvolverse más o menos normativamente. Efectivamente, sólo acceden a estos establecimientos quienes han reunido el dinero suficiente, ya sea mendigando o haciendo "changuitos", y quienes pueden reproducir aunque sea parcial mente un conj unto de interacciones pautadas de antemano. Quienes pueden presentarse en ellos en estado de ebriedad u otro estado que implique una considerable alteración de la interacción pautada encuentra generalmente dificultades de acceso. Asimismo, éste último puede ser objeto de restricción en base a un criterio diferente, tal como el que se presenta en los casos en que la no posesión de documentación identificatoria legal podía significar el cierre de la entrada al establecimiento. Dado que esta percepción generalmente no coincidía con el status legal de las personas, más allá de no poseer documentación identificatoria, vemos que el contexto más cercano a "la casa" -las "hospederías" puede ser también una fuente de prejuicios y discriminación que atraviesa el proceso de configuración de la identidad entre las personas sin hogar.

Por último, en esta fase la persona inicia un proceso de re-invención de su mismidad, cuyas expresiones más evidentes son el abrazo de una identidad social estigmatizante -y la auto-identificación como torrante 0 , en otros casos, como caminante- que puede consolidarse durante las dos fases siguientes del proceso. Lo que interesa en este caso es la proyección, entre prácticamente todas las personas de estas categorías que vivían sin hogar entre uno y cinco años, de conductas o atributos estigmatizantes. Estos atributos se expresan en la vida cotidiana de una manera dramática a partir de un eje estético -rostro demacrado, desaseo corporal, vestimenta sucia o roída, hedor- y ético -ligado a una estética del dolor y el abandono, vinculada a su vez a una estrategia de sobrevivencia sostenida en el modelo de caridad vigente en la sociedad nacional ${ }^{24}$. Otro de los atributos relevantes dentro de este grupo es el alcoholismo y todo un cortejo de consecuencias negativas que su abuso trae consigo.

El uso excesivo del alcohol está asociado a un consumo cultural extendido

\footnotetext{
${ }^{23}$ Lo que nos advierte el status inusitado que representaría la categoría dentro del mundo social o, en otro plano, la ambigüedad implicada o contenida en su afirmación por parte del discurso institucional.

${ }^{24}$ Me refiero fundamentalmente al modelo de caridad cristiano que justifica y promueve la limosna y la ayuda social hacia el desposeído.
} 
dentro de la sociedad chilena y especialmente dentro de la sociedad regional que, desde el punto de vista de los actores se define desde diversos planos que contrastan frente al punto de vista especializado, el que lo define como una "toxicomanía", o sea, una práctica que activa "la potencia de un deseo que se ha vuelto insaciable y cada vez más devorador, hasta tal punto que la satisfacción nunca definitiva se transforma aquí en tolerancia y en dependencia: fijación en productos de los que ya no se puede prescindir para no sufrir demasiado" (Sissa, 1997: 13). En este marco, el placer viene a calmar el sufrimiento y se transforma en "placer negativo". Lo que nos interesa recalcar aquí es que el cuerpo pasará a ser aquí una especie de mapa biográfico y moral en el que la persona ira dejando claramente inscrita su experiencia de vida sin hogar en la unidad o discontinuidad de sus vivencias y deseos.

En este marco, el torrante sin hogar encarna una identidad social y personal desacreditada, aunque no plenamente privada de la posibilidad de su restauración, basada en la frustración, la resignación, la obstinación y el auto-abandono a conductas socialmente reprochables - y por ende objetos de discriminación- como la de beber alcohol en exceso, la que incide en la emergencia de otros atributos y actitudes psicosociales: despreocupación por el cuerpo y el cuidado de la salud, desaseo, refracción al trabajo instituido, daño psico-orgánico, arrebatos de violencia, despecho e irritabilidad, etc.. El caminante, en tanto, se caracteriza principalmente por su nomadismo, su dependencia alcoholica, su preferencia por la calle como contexto de sociabilidad, la práctica del "macheteo" ${ }^{25}$ y la mayor tendencia gregaria. A pesar de presentar un aspecto físico similar al del torrante, el caminante encarna una actitud más hedonista y menos trágica ante la vida que aquél. Probablemente en este caso, la edad juegue un papel importante.

Entre una y otra fase pareciera no existir una brecha muy visible que las separe. Lo que se observa es una especie de yuxtaposición e imbricación compleja de elementos. Durante la fase de desvinculación la persona experimenta las primeras sensaciones de vulneración de su integridad que lo lleva a desarrollar una serie de estrategias de auto-protección sin las cuales el mundo de la calle sería prácticamente imposible de vivir y llegar a convertirse en un territorio existencial. La violencia y la locura, así como la dramatización del dolor y la apariencia de abandono pueden ser algunas de estas estrategias. Así, durante la fase de vulneración de la integridad propiamente tal el suj eto experimenta las consecuencias directas de su proceso de desvinculación del mundo de la vida social (familia, amistades, vecinos), así como de los sistemas sociales (trabajo, asistencia social, salud, protección social): el reproche y rechazo social, la desprotección y la exposición a las violencias urbanas de todo tipo: de los pares más jóvenes o más fuertes, de los sistemas de control social, de las pandillas juveniles, incluso de los perros. Hasta entonces todas estas experiencias de que ha sido objeto se han colado profundamente en su ser y han remodulado sus nociones del mundo, la sociedad y el yo.

Cuando la persona desarrolla prácticas de alcoholismo o cuando proyecta desórdenes psíquicos (en el caso de los perfiles de torrantes - caminantes y "alucinatorios", respectivamente), se da paso a otras nuevas vulneraciones: la persona puede experimentar estados de profunda inestabilidad psicoorgánica, o bien de deterioro de las competencias comunicativas que le permitirían, en otras condiciones, establecer relaciones de reciprocidad mínima. En estas circunstancias, la malla de interacciones que sostienen el mundo de la vida social de las personas se hace cada vez más reducida. Los torrantes y/o caminantes interactúan sólo con fines instrumentales, para satisfacer necesidades creadas dentro de sus nuevas condiciones de vida: mendigar para comprar bebidas alcohólicas, alimentarse o reunir

\footnotetext{
${ }^{25}$ Término nacional usado generalmente por los sectores juveniles para designar una forma de mendicidad cuyo propósito principal es reunir dinero para comprar bebidas alcohólicas.
} 
el dinero para hospedarse. En el caso de las personas con perfil "alucinatorio" se da una ausencia de contactos interpersonales, por lo que se despliegan estrategias de vida egocentradas, la que no es exclusiva de esta fase sino que pueden hacerse presentes desde el inicio mismo del proceso.

Cabe destacar que en estos dos perfiles la persona es víctima de sí misma: su propio vicio o su propia locura son los enemigos mortales con los que debe aprender a convivir. De este modo, vivir situaciones de vulneración de la integridad es vivir de cara a un proceso de deterioro progresivo de las fuentes que garantizan y proyectan la unidad afectiva, valórica, intelectual y corporal del ser humano. Dado que el cuerpo es el soporte material en el cual queda inscrita la tonalidad de nuestro vínculo con nosotros mismos y nuestro entorno social y con el mundo en general, es en el cuerpo donde más evidentemente uno puede observar las marcas de las respectivas carreras marginales que las personas sin hogar llevan a cabo en su tránsito por el mundo. En efecto, la apariencia física y el estado de salud son ejes que ocupan un lugar notorio dentro de este tránsito.

En nuestro análisis etnográfico inicial de las "carreras" marginales (Berho, 2000), descubrimos algunas demarcaciones sociales invisibles que se establecen cuando las conductas habituales se desgastan al punto en que el cuerpo se pone putrefacto o está a punto de estallar, como ocurrió con tres hombres que conocí, dos de los cuales tenían heridas corporales infectadas (uno de ellos con su pierna agusanada) y un tercero una hernia del tamaño de una pelota infantil. Hay aquí unos cuerpos indiferentes consigo mismos, pues sus centros están fuera de ellos: en el auto-abandono de la conciencia, a la deriva de una jornada de excesos, en las cantinas, las "picás" 26 y las borracheras. Todo esto puede expresarse, en última instancia, en alienación.
Entre los torrantes esta fase constituye un momento de agravamiento de la desvinculación unida al desarrollo de una identidad social indeseable aborrecida incluso por sí mismos, que refuerzan la simbolización de la experiencia de la persona como una "caída" (ver abajo). Ya sea para sentirse feliz, para pasar la noche, pasar el frío, apaciguar las "ganas de tomar" (volver a beber), el insaciable apremio del deseo va quedando de manifiesto dramáticamente en el cuerpo de la persona. Algunas de estas manifestaciones han quedado registradas visualmente y su análisis muestra los cambios fisonómicos que experimenta la persona, a veces en muy poco tiempo y que ésta tenga consciencia de ellos. "La despreocupación por las cosas y por la gente se transforma en necesidad absoluta, en preocupación dominante por un único objeto: el producto que, se suponía, iba a dispensarnos de toda inquietud" (Sissa, Op. Cit.: 18). "En cuanto el hábito se instala, el principal cuidado que se tiene es sobre todo, el de evitar todo cuidado. La incuria en el mantenimiento del cuerpo no demora, por otra parte, en manifestar la pérdida del amor propio" (Ibíd.: 35-36).

La repetición de la práctica a que conduce la dependencia al alcohol no es parte de la reflexividad del actor, aunque se asocie a la posibilidad de "anular las preocupaciones, negociar con la incompletud, la dificultad, el sufrimiento" (Ibíd.: 16). La anulación de las preocupaciones mediante el uso excesivo del alcohol genera un régimen de nuevas preocupaciones: la sustancia monopoliza la vida y reemplaza todo tipo de interés volviéndose en lo único importante y absorbiendo la mayor parte del tiempo. En estas circunstancias, la persona pierde el apetito, deja de comer o se alimenta muy mal, adelgaza considerablemente, bajan sus defensas, su piel se reseca, desarrolla halitosis y una indeleble angustia lo atraviesa. Los niveles de tolerancia a la sustancia entre los torrantes llegan a ser muy significativos

\footnotetext{
${ }^{26}$ Expendios de bebidas alcohólicas de bajo costo y de frecuentación habitual.

27 Sin contar con datos promediales, algunas personas pueden llegar a beber diariamente hasta cinco litros de vino o 1,5 litros de ron o cognac. Debe considerarse, además, que estas bebidas son de la peor calidad expendida en el mercado.
} 
durante esta fase ${ }^{27}$.

Las principales adaptaciones que se registran y que conducen a la adquisición de una identidad marginal tienen que ver, a estas alturas del proceso, con la resignificación del sí mismo y de la calle y de las experiencias de desvinculación social como territorios existenciales; el desarrollo de estrategias de sobrevivencia que desafían los cánones económicos del mérito y la iniciativa individual capitalista; y la actitud ante la vida.

En relación con la resignificación de la calle como territorio existencial, observamos que esta es una afirmación que hacen, en general, quienes ven en la calle un contexto que, a pesar de su violencia, es capaz de acoger a los más desposeídos. "La calle es mi madre" -señaló una vez un torrante ya fallecido. La calle, en este sentido y a pesar de todo lo que podemos imaginar, es re-significada como un contexto de estabilidad, es decir, como el hogar mismo. Asimismo, la calle constituye un territorio que tiene su propio recorrido: con una partida, una estancia, planicies, pliegues y un final. La seguridad que prodiga la madre, la calle también la puede dar. Es cosa de saber dónde buscar, a quién recurrir, a qué horas producir los desplazamientos, cuándo entrar en escena y en qué momento retirarse. Esto sólo cobra real significado en el caso de aquellos que han alcanzado un conocimiento íntimo de la vida en la calle, es decir, tras haber vivido a la sombra de ésta, cobijándose en su seno del frío y de la lluvia, comiendo de su comida, bebiendo de sus líquidos. Aunque con el paso del tiempo pareciera diluirse el sentimiento de inseguridad que emana de la calle, esto no significa que ésta sea segura o protegida: la mayor parte de las personas que llegan a esta fase sufren desequilibrios asociados a la vida en la intemperie -enfermedades respiratorias (TBC), estomacales (úlceras, cólicos, gastritis) y traumatológicas (a causa de quebraduras o fracturas y de la falta de comodidades ergológicas) que aumentan considerablemente el riesgo vital.

La desvinculación primaria que han experimentado Ileva a las personas a simbolizar la vida en la calle como contexto existencial en el que simultáneamente se registran relaciones más o menos estandarizadas, contingentes y azarísticas de benevolencia, jocosidad, indiferencia, abuso y violencia. Así, las interacciones que desarrollan las personas sin hogar, especialmente las "experimentadas" y "atrincheradas" con perfil torrante, caminante, "alucinatorio" o "profesional", trazan un continuo relacional que va de la caridad, basada en la compasión, al más contundente de los rechazos, pasando por la invisibilidad y el humor que sus respectivas figuras parecieran concitar.

Dentro de las principales estrategias de sobrevivencia identificadas a partir del acercamiento de campo, tenemos las siguientes, de acuerdo a sus respectivas orientaciones: 1) económicas, 2) relacionales, y 3) de defensa o contención subjetivas. Estás últimas se orientan a impedir el acceso de un externo al reino privilegiado de las biografías, especialmente cuando la antigua identidad era la que alguien que gozaba de cierta respetabilidad y prestigio social (como en el caso de ex - comerciantes, ex -profesionales, o ex - funcionarios), o sencillamente cuando para la personas se trata de un asunto que la sacude emocionalmente. También se observa un control de la información relativa a la identidad personal entre las pocas personas que tienen antecedentes penales. En estos casos, la persona puede sostener relaciones de evitación tendientes a no ser descubierta, eludiendo así la posibilidad de que su actual situación se vea aún más exacerbada a causa de un nuevo estigma que virtualmente pueda imponerse. En un plano menos virtual, otra de las estrategias de defensa y protección es la de tener y llevar consigo perros, los que hacen las veces de "guardianes" frente a eventuales peligros y de "guateros" para calentarse en las noches.

El conocimiento de estos casos sugiere que mientras la persona busca borrar su antigua identidad, "guardando en su corazón" pequeños vestigios de ésta, el proceso de adaptación y desarrollo del estilo de vida marginal lo lleva a 
re-inventarse una nueva identidad. Así, entre los torrantes existe la tendencia a cambiarse de nombre o a adoptar apodos. Estos apodos constituyen verdaderas marcas dentro del proceso de conversión identitaria que hemos detectado entre las personas sin hogar "experimentadas" y "atrincheradas". Las personas con perfiles "alucinatorios" - mas bien sus padecimientos-, en tanto, tienden a anular la identidad actual y la pasada. Esta tendencia se vincula directamente al proceso que hemos denominado de anonimación, específicamente porque, a diferencia de la conversión identificada entre los torrantes y caminantes "atrincherados" o "experimentados", en él la persona pierde el control de sí mismo respecto de los marcos de comunicación generales que atraviesan la vida social. Esto es lo que lleva a que la persona adopte una apariencia desaliñada y que a veces incluso deje de llevar vestimentas.

Si en la fase anterior los torrantes "experimentados" ya son presa del monopolio de la existencia y la sustitución de todo tipo de intereses que impone la dependencia alcohólica, en esta última fase la persona experimenta también una especie de anonimación ontológica, en el sentido de que su vida puede llegar a perder completamente consistencia existencial y temporal. En los casos conocidos más directa e íntimamente, la persona se concibe a sí misma como alguien que experimenta una "caída" existencial que lo puede llegar a convertir en un animal, particularmente en un perro. Así, es común oír decir de boca de estos torrantes "valgo menos que un perro", "vivo como los perros, tirado en la calle", etc. En otros casos, la persona vivencia su situación como una especie de auto-escenificación de la tragedia del mundo. Su persona puede asimilarse, desde la tradición religiosa, a la figura de Cristo en la Tierra. Mientras en el primer caso, la persona adopta un perfil que se auto-clausura a la posibilidad de experimentar un agenciamiento tendiente a recomponer creativamente su identidad, en el segundo la persona usa para su provecho las convenciones sociales ligadas a la tradición religiosa, especialmente católica, predominante aún en la cultura nacional.

Sólo en unos pocos casos de "profesionales" "atrincherados" se producen construcciones positivas en torno a la mismidad, a pesar de no existir un ejercicio de los derechos sociales y civiles ni siquiera mínimo, como en el caso de algunos torrantes y "alucinatorios". Entre estas personas la vida es concebida como un estado particular y/ o una opción a partir de la cual se busca refundar la propia identidad. Así se explica que entre ellos exista una permanente preocupación por el estado del cuerpo, la mente y la salud, los que son objeto de interesantes simbolizaciones y metáforas, siendo las más representativas las ligadas al cuerpo: el cuerpo como "templo" o "lugar sagrado"; y el cuerpo como "máquina" o "rodamiento" o el cuerpo como "reloj".

Las palabras y la actividad físicamental pueden tener, en casos como estos, el poder de dar vida en medio de los desechos y los "desvíos" de la ciudad. A juicio de uno de estos "profesionales", "se vive porque se es capaz de hablar y moverse, "desarrollar el lenguaje... y el don de las extremidades". El poder está en la magia de las palabras y en un cuerpo vivo que continuamente constatan la existencia de la persona con sólo darse cuenta que las cosas pueden ser nombradas" (Berhó, Op. Cit.: 49). De allí que esta persona dedicara gran parte del tiempo a "hacer oraciones", "componer cantares" y "ejercitar el don de las extremidades", esto es, "limpiar la ciudad" recogiendo desechos que transporta de un lugar a otro y que acumula en lo que denomina su "mampara" u hogar. Al mismo tiempo, en varias oportunidades la observé "haciendo pesas" con grandes rocas del río o bien con fierros y neumáticos viejos que colgaba a brazos y cuello durante horas para sentirse vivo 0 , en sus propias palabras, "para estar a nivel".

Las estrategias relacionales observadas se trasponen con las estrategias antes señaladas $y$, especialmente, con las estrategias económicas de sobrevivencia: una barba larga, la ausencia de una pierna o un brazo, la ceguera, la vestimenta harapienta, 
UNIVERSIDAD CATÓLICA DE TEMUCO

la suciedad, la apariencia de estar desnutrido, abatido y enfermo son todas marcas visibles que pueden afectar la sensibilidad del ciudadano común y corriente, al punto que su conmoción lo lleva a dar limosna o a "tenderle una mano al "necesitado"" 28 .

Por último, cabe señalar que algunas personas sin hogar han podido restituir su identidad marginal y re-iniciar una vida en la que, en general, han debido hacer esfuerzos de toda naturaleza para recuperar la confianza perdida entre sus seres queridos. La posibilidad de efectuar cambios significativos y salir de la marginalidad es una realidad, sobre todo entre quienes tienen la voluntad y buscan 0 aceptan la ayuda para hacerlo. A nuestro juicio dos son los factores que actúan en que esto sea así: por un lado, la cercanía que puede existir entre la persona y alguna institución de ayuda $y$, por otro lado, el nivel de conciencia y discernimiento subjetivo que puede tener la persona de su situación vital. Este último aspecto puede estar relacionado, a su vez, con las creencias religiosas de las personas y la confianza que tienen en que su estado actual no es más que "una prueba del de arriba". En los casos en que no existe disposición al cambio, en tanto, se trata de personas que presentan un fuerte sentido de resistencia y resignación y porque consideran, también desde una perspectiva religiosa, que su situación responde a un designio providencial que los trasciende radicalmente y frente al cual no hay nada que puedan hacer.

\section{BIBLIOGRAFÍA}

BAUMAN, ZYGMUNT (2003), "De peregrino a turista, o una breve historia de la identidad". En Stuart Hall y Paul du Gay (Comps.), Cuestiones de identidad cultural. Amorrortu, Buenos Aires.

BERHO, MARCELO (1998), "Esbozo para una etnografía del vagabundo". En CUHSO, Volumen IV, № 1: 38 - 43.

BERHO, MARCELO (2000), "Una carrera hacia Ios bordes de la sociedad". En CUHSO, Volumen V,
№ 1: $45-56$.

BERHO, MARCELO (2003), "Perfiles socioculturales de personas sin hogar. Informe de sistematización", Programa de Apoyo a Personas Abandonadas en la Calle, DIDECO-Municipalidad de Temuco, Centro de Estudios Socioculturales, Universidad Católica de Temuco.

BERHO, MARCELO (2003), "Personas sin hogar en Temuco. Enfoque antropológico aplicado". En Nicolás Richard (Ed.), Movimiento de campo en torno a cuatro fronteras de la antropología chilena. ICAPI, Guatemala.

BERHO, MARCELO (2005), "Antropología de la marginalidad extrema". En ANTHROPOS № 207: $43-53$.

CABRERA, PEDRO (1998), Huéspedes del aire. Sociología de las personas sin hogar en Madrid. Pontificia Universidad de Comillas, Madrid.

CASTEL, ROBERT (1999), Las metamorfosis de la cuestión social. Una crónica del salariado. Paidós, Buenos Aires.

CASTEL, ROBERT (2003), Propiedad privada, propiedad social, propiedad de sí mismo. Conversaciones sobre la construcción del individuo moderno. Homo Sapiens, Rosario.

DA MATTA, ROBERTO (2002), Carnavales, malandros y héroes. Una interpretación sociológica del dilema brasileño. Fondo de Cultura Económica, México.

FOUCAULT, MICHEL (1993), Historia de la locura en la época clásica. Tomo II. Fondo de Cultura Económica, México.

GRIGSBY, C., BAUMANN, D., STEVEN, G. Y ROBERTS - GRAY, C. (1990), "Desaffiliation to entrenchment: A model for understanding homelessness". En Journal of social issues 46 (4): 141 - 156.

GOFFMAN, ERVIN (1991), Estigma. La identidad deteriorada. Amorrortu, Buenos Aires.

SISSA, GIULla (1997), El placer y el mal. Filosofía de la droga. Manantial, Buenos Aires.

\footnotetext{
${ }^{28}$ El etnógrafo puede dar limosna como un camino potencial para acceder a las personas e iniciar una relación etnográfica. Otro método de acceso y establecimiento de contacto es el de visitar las instituciones de servicios.
} 
